\title{
Grundtvig-litteratur 2001-2005: En bibliografi
}

\author{
Af Aage Jørgensen
}

Nedenstående bibliografi over Grundtvig-litteratur 2001-2005 viderefører tilsvarende bibliografier i Grundtvig-Studier 1968, 1971, 1974, 1979, 1984, 1991, 1997 og 2001 (kumuleret udgave - dækkende årene 1963-1985 offentliggjort 1986).

Stoffet er ordnet efter bibliografiske kriterier frem for efter emnekredse. Tidsrummet gælder ikke absolut, idet enkelte bidrag af ældre og nyere dato er medtaget. Arbejdet er afsluttet 1.5.2006.

Med hensyn til avisstoffet (artikler fortegnet nedenfor i afsnit 6, samt anmeldelser fortegnet i forbindelse med de arbejder, de omhandler) gælder, at bibliografien ikke gør krav på fuldstændighed. Medtaget er i alt væsentligt, hvad også Artikelbasen (den elektroniske videreførelse af Dansk artikelindeks og Dansk anmeldelsesindeks) har fundet det rimeligt at redde fra glemsel.

\section{Bibliographica}

Jørgensen, Aage, "Grundtvig-litteratur 1997-2000. En bibliografi", Grundtvig-Studier 2001, 229-257.

\section{Udgaver}

Grundtvig Proedikener $i$ Vartov 1839-42, I-IV, udg. af Jette Holm, Elisabeth A. Glenthøj, Lars Toftdahl, Leif Kallesen, Johannes B. Glenthøj i samarbejde med Christian Thodberg, 2003, 542, 427, 457 og 498 s. (I: 1839-40; II: Kirkeåret 1840-41; III: Kirkeåret 1841-42; IV: Christian Thodberg, Indledning og kommentar [..]). (Anm.: Jørgen Bo Christensen, Prcesteforeningens Blad, LXXXXIV, 2004, 786-791; Anon, Kristeligt Dagblad 1.5.2004; Mikkel Wold, Information 6.3.2004).

\section{Bøger}

Allchin, A. M., Grundtvigs kristendom. Menneskeliv og gudstjeneste, overs. af Jakob Balling, 2002, 302 s. (Anm.: Jens M. Steffensen, Religionslcereren, 2003, nr. 2, 76-77). (Original title: N. F. S. Grundtvig. An Introduction to his Life and Work; Århus og London, 1997).

Auken, Sune, Sagas spejl. Mytologi, historie og kristendom hos N. F. S. Grundtvig, 2005, 735 s. (Disputats forsvaret på Københavns Universitet 3.6.2005; engelsk resumé, 632-643). (Jf. Thorkild C. Lyby, "Odin og Hvide Krist [...]”, Grundtvig-Studier 2005, 144159). (Anm.: Jørgen Elbek, Litteraturmagasinet Standart, XIX:3, 
2005, 53; Charlotte Ellermann, Prcesteforeningens Blad, LXXXXV, 2005, 932-933; Carl Henrik Koch, Kritik, nr. 178, 2005, 72-76 [replik af Sune Auken, nr. 179, 2006, 133-136]; Anon, Religion 2005, nr. 4, 61-62; Anon, Politiken 1.6.2005; Anon, Weekendavisen 3.6.2005; Anon, Jyllands-Posten 3.6.2005; Anon, Kristeligt Dagblad 3.6.2005; Anon, Folkeskolen, 2005, nr. 28-32, 38 og 40). (Jf. Søren Kassebeer, interview med SA, Berlingske Tidende 28.5.2005).

Bjerg, Svend, Gud først og sidst. Grundtvigs teologi - en loesning af Den christelige Børnelaerdom, 2002, 202 s. (Anm.: Hans Raun Iversen, TEOL-Information, nr. 27, 2003, 39-43, Dansk teologisk Tidsskrıft, LXVI, 2003, 76-78; Erik Kelstrup, Grundtvig-Studier 2005, 211-216; Ole Buchardt Olesen, Prcesteforeningens Blad, LXXXXIII, 2003, 124-126; Allan Poulsen, Religionslcereren, 2003, nr. 3, 65-66; Mikkel Wold, Information 2.1.2003).

Brovst, Bjarne Nielsen, Grundtvigs sloegt og barndom, 2003, 223 s. (Anm.: Runa J. Kähler, Kristeligt Dagblad 9.12.2003).

Brovst, Bjarne Nielsen, Den unge Grundtvig og en familietragedie, 2004, 253 s. (Anm.: Doris Ottesen, Kristeligt Dagblad 2.12.2004; Mette Winge, Politiken 15.1.2005); genudgivet i Højskolebladet 2005, nr. 1, 28.

Brovst, Bjarne Nielsen, Den unge Grundtvigs lidelser, 2005, 231 s. (Anm.: Anon, Højskolebladet, 2006, nr. 1, 12; Anon, Kristeligt Dagblad 16.11.2005).

Bugge, Knud Eyvin, Grundtvig og slavesagen, 2003, 226 s. (Skrifter udg. af Grundtvig-Selskabet, 35). (Engelsk resumé, 201-208). (Anm.: Carsten Bach-Nielsen, Kristeligt Dagblad 16.10.2003; Erik Hesselager, Prcesteforeningens Blad, LXXXXIV, 2004, 465466; Jes Fabricius Møller, Grundtvig-Studier 2005, 208-210, og Dansk Kirketidende, CLVI, 2004, 59-60; Laust Riis-Søndergaard, Højskolebladet, 2003, nr. 17, 15; Mikkel Wold, Information 23.10.2003).

Carlsen, Arne (red.), Grundtvig \& Europe. Anthology, 1998, 55 s. (Bidrag om "Lifelong Learning" af Lars Høgh Hansen, Alice Jensen, Jytte Wagner, Per Himmelstrup, Verner Ljung og Laue Traberg Smidt).

Heggem, Synnøve S., Kjærlighetens makt, maskerade og mosaikk. En lesning av N. F. S. Grundtvigs Sang-Vark til den Danske Kirke, Oslo, 2005, viii, 528 s. (Disputats, præpubliceret af Det teologiske Fakultet, Universitetet i Oslo; Acta Theologica, nr. 11). (Jf. Arild Mikkelsen, Folkehøgskolen, 2005, nr. 4-5, 25-26).

Holm, Anders, Historie og efterklang. En studie i N. F. S. Grundtvigs tidsskrift 'Danne-Virke', 2001, 139 s. (Anm.: Stefan Lamhauge Hansen, Fønix, XXV, 2001, 246-249; Niels Højlund, Højskolebladet, 2001, nr. 8, 8-9). 
Klippenberg, Arnt Olav, Kcerligheds dråber (...) N. F. S. Grundtvigs lidenskab og hemmelige laengsler. På dansk ved Stefan Hestnes, 1997, 64 s. (Noder ved Øystein Ellingsen, 41-58, originaltekster, 59-64).

Kulich, Jindra, Grundtvig's Educational Ideas in Central and Eastern Europe and the Baltic States in the Twentieth Century. 2002, 209 s. (Anm.: Agnieszka Bron, Grundtvig-Studier 2005, 217-220; Birte Fahnøe Lund, Dansk Kirketidende, CLVII, 2002, 322-323).

Mikkelsen, Arild, Grundtvig for begynnere ... og oss andre. Fire essays om grunnlagstenkning $i$ norsk folkehøgskole, Oslo, 2002, $78 \mathrm{~s}$.

Pedersen, Ole, Den levende vekselvirkning. Grundtvig, Kold og undervisningen i dag, 2003, 344 s. (Anm.: Mikael Holt, Kristeligt Dagblad 17.6.2003; Mikkel Wold, Information 2.3.2004). (Cf. Morten Mikkelsen, Kristeligt Dagblad 13.5.2003: interview med $\mathrm{OP}$ ).

Sanders, Hanne \& Ole Vind (red.), Grundtvig - nyckeln till det danska? Göteborg/Stockholm, 2003, 303 s. (Indhold: Hanne Sanders, "Indledning", 7-12; Ole Vind, "Grundtvig og det danske - med sideblik til Sverige", 13-37; Tine Damsholt, "Grundtvig og de ansvarlige borgere. En diskussion af Grundtvigs politiske ideer om demokrati, frihed og ansvarlighed set som udtryk for moderne ledelsesrationaler", 38-59; Urban Claesson, "Grundtvig, bonderörelse och folkkyrka. En historisk jämförelse mellan Danmark och Sverige", 60-90; Yvonne Maria Werner, "Grundtvig - en kyrkofader för danska katolska konvertiter runt sekelskiftet 1900?", 91-125; Ola Fransson, “I skuggan av Grundtvig”, 126149; Kim Arne Pedersen, "Den teologiske Grundtvig - forskning siden Anden Verdenskrig", 150-179; Hans Hauge, "Nynationalismen og markedets metafysik. Søren Krarup og Ebbe Kløvedal Reich som moderne grundtvigianere", 180-200; Bosse Bergstedt, "Rösten och tecknet. En nyläsning av Grundtvig - skapad ur mötet mellan dansk och svensk kunskapsbildning", 201-224; Uffe Jonas, "Poetisk videnskab. Grundtvigs universitetsdrøm som kosmopolitisk dannelses-projekt", 225-281; Christian Thodberg, "Nikolai Frederik Severin Grundtvig. Artikel från Den store danske Nationalencyklopædi”, 283-290). (Anm.: Laust Riis-Søndergaard, Højskolebladet, 2003, nr. 18, 18; Niels Thomsen, Kristeligt Dagblad 25.10.2003; Mikkel Wold, Information 23.10.2003).

Reich, Ebbe Kløvedal, Frederik. En folkebog om N. F. S. Grundtvigs tid og liv. Billedredaktion: Ole Kragh. 4. udg., 2002, 402 s. (1. udg., 1972).

Wigh-Poulsen, Henrik, m.fl. (red.), Grundtvig - Kierkegaard. En samtale på høje tid, 2002, 224 s. (Foredrag fra Grundtvig/Kierkegaard-ugen 2002: Niels Henrik Gregersen, "Når der bliver mere ud 
af mindre. Grundtvigs menneskesyn", 11-30; Ebbe Kløvedal Reich, "Modsigelsen - en grundtvigsk diagnose", 31-42; Pia Søltoft, "For Gud er Alt muligt", 43-57; Kim Arne Pedersen, "'Sjæle og kroppe i tusindtal ...'. Om sammenhængen mellem menneskesyn og kirkesyn hos Grundtvig, undersøgt med baggrund i Kierkegaards forfatterskab", 59-89; Kresten Drejergaard, "Grundtvigs vej fra studerekammeret til gudstjenesten", 91-109; Morten Kvist, "Grundtvigs kirkesyn. Om 'den kirkelige anskuelse' og sakramental kristendom - afslutningen på en historie eller begyndelsen på en ny?", 111-123; Britta Schall Holberg, "Det forpligtede liv om at være en del af en historisk tradition", 125-132; Peter Tudvad, "Kierkegaard mod konstitutionen - 'Medicin mod en Frihedsruus", 133-148; Svend Auken, "Det politiske hos Kierkegaard og Grundtvig", 149-157; Marianne Jelved, "Den enkelte og fællesskabet", 159-166; Henrik Wigh-Poulsen, "Melankoli og profeti. Om Grundtvig, Lundbye og guldalderkunsten", 167-186; Joakim Garff, "'Hvad har dog ikke denne Pen formaaet ...?'. Om det æstetiske hos Kierkegaard", 187-205; Svend Erik Werner, "Tålt ophold - om den autonome musik, Grundtvig og Kierkegaard i et nutidsperspektiv", 207-222). (Jf. Otto Bertelsen, "Samtalen mellem Grundtvig og Kierkegaard", Grundtvig-Studier 2003, 204-212). (Anm.: Ole Burchardt Olesen, Prcesteforeningens Blad, LXXXXIII, 2003, 506-508).

Wingren, Gustaf, Menneske og kristen. En bog om Irenæus og Grundtvig, overs. af Knud Simon Christensen, 2004, 141 s. (Anm.: Thomas Reinholdt Rasmussen, Proesteforeningens Blad, XCV, 2005, 135-136; Niels Thomsen, Kristeligt Dagblad 10.11.2004). (På svensk, 1983).

\section{Dele af bøger}

Auken, Sune, "N. F. S. Grundtvig (1783-1872)" i Marianne StecherHansen (red.), Danish Writers from the Reformation to Decadence, 1550-1900, Detroit, 2004, 194-212. (Dictionary of Literary Biography, 300).

Ben-Yosef, Israel Aharon, Martin Buber on Adult Education, Tel Aviv, 1985, 134 s. (Heri: "The Influence on Buber's Ideas on Adult Education. N. F. S. Grundtvig”, 28-44). (Set i GrundtvigBiblioteket, Vartov).

Bering, P. H., "Grundtvig, naturret og solidaritet" i Leon Nikulin (red.), Litteratur og magt. Nordisk-baltisk littercert symposium (foredragssamling), 2000, 76-84.

Birkelund, Regner, Livs-Oplysning, 1999, 121-171 og 240-246 (2. del: "Grundtvigs pædagogiske tanker. Idégrundlaget for 'Forskolen i Højskolen"”). (Også 3. del, "Løgstrups etik- og æstetikforståelse. 
Livsoplysning i nyt lys!", har G-relevans).

Birkelund, Regner, "Grundtvig og demokratiet. Om oplysning, dannelse og demokrati” i Ove Korsgaard \& Uffe Jonas (red.), Poetisk demokrati. Om personlig dannelse og samfundsdannelse, 2001, 28-47.

Bjork, Robert E., "N. F. S. Grundtvig's 1840 Edition of the Old English 'Phoenix'. A Vision of a Vision of Paradise" i Mark C. Amodio \& Katherine O'Brien O'Keeffe (red.), Unlocking the Wordhoard. Anglo-Saxon Studies in Memory of Edward B. Irving, Jr., Toronto/Buffalo/London, 2003, 217-239.

Brovst, Bjarne Nielsen, Guldalderens Nytaarsgaver og $H . C$. Andersen, 2005/2006, 105-110, 117-122 og 131-134.

Brun, Jens, "Grundtvigs begreb om "Christelighed"" i hans, Tro, håb og korlighed. Grundtvigske meditationer, [2004], 9-14. (Anm.: Arne Mårup, Prcesteforeningens Blad, XCV, 2005, 61-62).

Buber, Martin, Menneskets vej efter den chassidiske loere, 1991, $60 \mathrm{~s}$. (Efterord af Palle Dinesen, om G og B spec., 49-53).

Carlsen, Jørgen, "N. F. S. Grundtvig. Mellem himmel og jord Grundtvig og den moderne verden" i Regner Birkelund (red.), Eksistens og livsfilosofi, 2002, 65-90.

Dahlén, Kerstin \& Anna Vallgårda (red.), Tradition og vision i nordisk folkeoplysning. Jubilaumsbogen, Nordens Folkelige Akademi, Kungälv, 1998. (Heri bl.a.: Bosse Bergstedt, "En Akademi för livet", 12-25, spec. 13 f; Ove Korsgaard, "Grundtvigs universitetstanker og videnskabssyn", 28-39).

Elbek, Jørgen, "Grundtvig i sidelys" i hans, Fra korlighedens tid, 2004, 21-41.

Erichsen, John, Rønnebceksholm. En herregård ved Naestved, 2002, 125 s. (Heri om G og Marie Toft, 62-69).

Fafner, Jørgen, Dansk vershistorie 2: Dansk Verskunst, II,2: Fra romantik til modernisme, 2000, 263-276, m.fl.st.

Fibiger, Johannes \& Gerd Lütken, Litteraturens veje. 2. udg., 2003,150-152. (1. udg., 1996).

Gemzøe, Anker, "Tyske piger synger bedre, men ... Den sammenlignende nationalfølelse hos Adam Oehlenschläger med særligt henblik på 'Hiemvee' (1805) og med sideblik på St. St. Blicher og N. F. S. Grundtvig m.fl." i Sven Hakon Rossel (red.), Der Norden im Ausland - das Ausland im Norden. Formung und Transformation von Konzepten und Bildern des Anderen vom Mittelalter bis heute. 25. Tagung der IASS (International Association for Scandinavian Studies) in Wien, 2.-7.8.2004. Wien, 2006, 269-280. (Wiener Studien zur Skandinavistik, 15).

Gjesing, Knud Bjarne, "N. F. S. Grundtvig" i Klaus P. Mortensen (red.), Litteraturens stemmer, 2. udg., 2003, 116-122. (Også i Klaus P. Mortensen \& Søren Schou (red.), Gads danske forfatter- 
leksikon, 2003, 208-215).

Gosse, Edmund, To Besøg i Danmark 1872 og '74. Dansk åndsliv gennemskuet af en engloender. På dansk ved Valdemar Rørdam. Genudgivet og med forord af Kristian Hvidt, 2001, 62-68. (1. udg., 1912).

Greenleaf, Robert K., Servant Leadership. A Journey into the Nature of Legitimate Power and Greatness. New York/Mahwah, NJ, 2002, 45-47.

Gregersen, Niels Henrik, "Nådespagten og menneskets frihed. N. F. S.

Grundtvigs tilføjelse til den augustinsk-reformatoriske nådelære" $\mathrm{i}$ Bo Kristian Holm \& Else Marie Wiberg Pedersen (red.), Nåden og den frie vilje, København 2006, 267-293.

Hansen, Bent, "Hvad skal vi med Grundtvig?" i En hilsen fra Odense Friskole, 2004, 12-14. (Smst.: Finn Slumstrup, "Grundtvigs nødvendighed for de frie skoler", 15-19).

Hansen, Knud, "Nogle grundbegreber i Grundtvigs tanker om folkelighed" i hans, Om at have mod til at leve, red. af N. H. Borup, m.fl., 2002, 182-198. (< Fønix, VIII, 1984, 220-33).

Hartby, Inger (red.), Gensyn med Christen Kold - en antologi, 2004, 220 s. (Heri bl.a.: Carsten Oxenvad, "Er Skolen virkelig en Troessag?", 101-128; Birte Fahnøe Lund \& Ole Kamp, "De grundtvigkoldske skoletanker i et nutidigt perspektiv", 129-152).

Hauge, Hans, "Dekonstruktionisme" i Johannes Fibiger, Gerd Lütken \& Niels Mølgaard (red.), Litteraturens tilgange - metodiske angrebsvinkler, 2001, 243-272. (Heri s. 263-270 læsning af "Strandbakken ved Egeløkke", aftrykt s. 431-435).

Heggem, Synnøve S., "Grundtvig, Nikolai Frederik Severin" i Mircea Eliade (red.), Encyclopedia of Religion, 2nd. ed., Woodbridge, CT, 2005, 3704-3706. (1. udg., I-XVI, 1987, uden G-artikel).

Helleberg, Maria, Danmarkshistorier for børn 2, ill. af Christian Würgler Hansen, 2003, 97-103 ("Grundtvig").

Henriksen, Aage, "Teologi og erfaring. Kierkegaard, Grundtvig, Goethe" i hans, Den eneste ene og andre essays, 2004, 93-107. (< Kritik, nr. 170, 2004, 50-56).

Hornbech, Birthe Rønn, "Grundtvig og ytringsfriheden", i hendes, Ret og rimeligt, 2004, 45-47. (Jf. "Mit liv med salmebog og højskolesang", 140-165).

Ipsen, Arne, Et hus på Christianshavn. Historien om Strandgade 4 og 4 B og ejendommens beboere, 2003, 45 s. (Flere afsnit om G og familie, spec. sønnen Svend).

Jensen, Carsten, "Livet i Camp Eden" i hans, Livet i Camp Eden. Essays, 2004, 9-30, spec. 11-16.

Jensen, Jørgen I., Mødepunkter. Teologi - Kultur - Musik. Artikler, 2004, 808 s. (Heri bl.a.: "Grundtvig og nutidens problemer med historien", 129-139 [< Almanak. Københavns Universitet, 1984]; 
"Kristendommens sammenhæng. Synsvinkler på Otto Møllers kritik af den liberale teologi", 326-363 [< Fønix, 1978]; "Forventningens teologi", 364-383 [< Teologi og tradition, 1988; om Frederik Helveg]; "Luther og Grundtvig - et oplæg", 439-466 [<Dansk Kirkeliv, 1983]; "Forsøg med romantik og kristendom", 656-682 [< Kaos og Kosmos, 1989]; "En indre sitren. Balancen mellem det klassiske og det romantiske", 683-688 [ $<$ Guldalderhistorier, 1994]; "Grundtvigsk bibelbrug", 689-702 [< Vartovbogen, 1978; forkortet]; "Historiens Palæstina", 703-711 [< Grundtvigianisme og nasjonalisme $i$ Norge $i$ det 19. århundre, 1996]; bibliografi 785-803).

Kjærgaard, Jørgen, Salmehåndbog, I: Salmehistorie. Med biografier af forfatterne i Den Danske Salmebog 2002; II: Salmekommentar til salmerne i Den Danske Salmebog 2002, 2003, 599, 730 s. (Det salmehistoriske afsnit omtaler G s. 169-72 og 180-86, cf. reg. s. 534; G-biografi s. 397-400; salmekommentaren meddeles i DSnummerorden [se $D S$, under "Salmernes forfattere"]).

Koch, Carl Henrik, Den danske filosofis historie, III: Den danske idealisme. 1800-1880, 2004, 595 s. (S. 79-85 om striden mellem H. C. Ørsted og G.).

Korsgaard, Ove, "Multikultur og nationalstat. Fejden mellem Grundtvig og Goldschmidt" i Marianne Østergaard (red.), Images of the World. Globalisering og kulturel mangfoldighed, 2001, 84-89.

Korsgaard, Ove, "Multiculture or National State. The Controversy between Grundtvig and Goldschmidt" i Marianne Østergaard (red.), Images of the World. Globalisation and Cultural Diversity, 2001, 84-89.

Korsgaard, Ove, Kampen om folket. Et dannelsesperspektiv på dansk

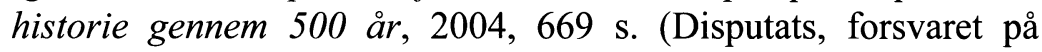
Danmarks Pædagogiske Universitet 30.4.2004). (Om G spec. s. 214-228, 264-267 og 277-285; cf. reg.).

Kværndrup, Sigurd, Grundtviga izglītības idejas" i Danijas folkehøjskoler šodien, 1993, 19-24. (Heftet, 40 s., udg. af Hørning Ungdomsskole, har også bidrag af Finn Slumstrup, Jørn Fugl, Jørgen Karlsen, Ebbe Lundgaard, Ove Korsgaard, Øivind Arnfred og Jakob Krog).

Larsen, Jesper Eckhardt, J. N. Madvigs dannelsestanker. En kritisk humanist $i$ den danske romantik, 2002, 97-101. (Studier fra Sprogog Oldtidsforskning, 337).

Levy, Jette Lundbo, Klaus P. Mortensen, Erik A. Nielsen \& Svend Skriver, Litteratur-historier. Perspektiver på dansk teksthistorie fra 1620 til nutiden, 2. udg., 2004, 123 (af KPM) og 171-173 (af EAN). Cf. reg. (1. udg., 1994).

Lodberg, Peter, "Grundtvig i økumenisk perspektiv" i hans, Dansker først og kristen så. Overvejelser om nationalitet og kristendom, 
2001, 87-105, 125-126 (note 18 ff). (< Grundtvig-Studier 1998, 157-175).

Lundgreen-Nielsen, Flemming, "N. F. S. Grundtvig" i John Chr. Jørgensen (red.), Dansk forfatterleksikon. Biografier, 2001, 145147. (I det tilhørende bind, Voerker, omtaler Sune Auken "PaaskeLilien", 233-234, "Nyaars-Morgen", 213-214 og "Sang-Værk til den danske Kirke", 247-248).

Lundgreen-Nielsen, Flemming, "The Special Case of Grundtvig: Poet, Philosopher, Politician, Educator" i Oskar Bandle m.fl. (red.), The Nordic Languages. An International Handbook of the History of the North Germanic Languages, I, Berlin/New York, 2002, 494502. (Handbücher zur Sprach- und Kommunikationswissenschaft, 22:1).

Lundgreen-Nielsen, Flemming, "Grundtvig and Romanticism" i Jan Stewart (red.), Kierkegaard and His Contemporaries. The Culture of Golden Age Denmark, Berlin/New York, 2003, 217-237. (Kierkegaard Studies. Monograph Series, 10). (< N.F.S. Grundtvig. Tradition and Renewal, 1983, 19-43).

Lyby, Thorkild C., "'Skolen for Livet'. Grundtvigs tanker om folkeoplysning" i Carsten Bach-Nielsen (red.), Dannelse, uddannelse, universiteter. Festskrift til Henning Lehmann den 31. januar 2002, 2002, 217-237.

Lykkegaard, Martin, "Sensei Grundtvig" i Henning Eichberg \& Bo Vestergård Madsen (red.), Idrottens enhed eller mangfoldighed, 2002, 31-40. (Bevægelsesstudier, 1).

Mellergård, Mogens, Psykiatrisk portratgalleri, 2001, 53-59.

Metz, Georg, Den danske sang, 2001, 107-139. ("Kommer hid, I piger små", 107-110; "Langt højere bjerge så vide på jord", 111-114; "Moders navn", 115-117; "Blomstre som en rosengård", 118-120; "Vær velkommen, Herrens år", 121-123; "Det var en sommermorgen", 124-127; "Det er så yndigt at følges ad", 128-131; "Et jævnt og muntert, virksomt liv", 132-135; "Den signede dag", 136-139).

Mikkelsen, Hans Vium \& Niels Thomsen (red.), Hvor blev det grundtvigske af? 2004, 203 s. (Heri bl.a.: Jørgen Gleerup, "Mellem Grundtvig og Nishida. Samtaler med en ung japansk student om det grundtvigske i det moderne", 9-23; Svend Auken, "Spor af Grundtvig (og Kierkegaard) i dansk politik", 107-117). (Anm.: Katrine Lilleør, Berlingske Tidende 4.9.2004; Jes Fabricius Møller, Dansk Kirketidende, CLVI, 2004, 113-115; Ole Burchardt Olesen, Proesteforeningens Blad, LXXXXIV, 2004, 792-793; Laust Riis-Søndergaard, Højskolebladet, 2004, nr. 16, 16; Lars Tjalve, Kristeligt Dagblad 26.2.2004).

Mitra, Tandra, Asoke Bhattacharya \& Jayanti Alam (red.), Education and Development. Proceedings of the Grundtvig International 
Conference held at Jadavpur University in January 1999, Jadavpur University, Kolkata, India, 2003, 176 s. (11 indlæg). (Anm.: S. A. J. Bradley, Grundtvig-Studier 2003, 224-229).

Møller, Jes Fabricius, Grundtvigianisme $i$ det 20. århundrede. 2005,

173 s. (Anm.: Johs. Nørregaard Frandsen, Dansk Kirketidende, CLVII, 2005, 388-390; Arne Mårup, Prasteforeningens Blad, LXXXXV, 2005, 793-794).

Pedersen, Gudmund Rask, "H. C. Andersen i prædikenen. Eventyr og evangelium" i Carsten Bach-Nielsen \& Doris Ottesen (red.), Andersen og Gud. Teologiske loesninger $i$ H. C. Andersens forfatterskab, 2004, 153-171. (Med inddragelse af G-salmer).

Rasmussen, Jens, En brydningstid. Kirkelige holdninger $i$ guldalderperioden 1800-1850, 2002, 178 s. (Odense University Studies in History and Social Science, 240). (Heri bl.a.: "N.F.S. Grundtvig og rationalisterne", 59-70; cf. reg.).

Rasmussen, Jens Rahbek, Modernitet eller åndsdannelse? Engelsk $i$ skole og samfund 1800-1935, 2003, 29-34. (Studier fra Sprog- og Oldtidsforskning, 339).

Reich, Ebbe Kløvedal, "Arne Haugen Sørensen, Grundtvig og kødets opstandelse" i Grundtvig, Marie og Arne Haugen Sørensen på Rønnebceksholm, 2003, 7-15. (Udstillingskatalog.)

Sigurðsson, Ingi, "Áhrif hugmyndafræði Grundtvigs á Íslendinga", Ritmennt. Ársrit Landsbókasafns Íslands, VIII, 2003.

Simonsen, Jørgen Bæk, Islam med danske øjne. Danskernes syn på

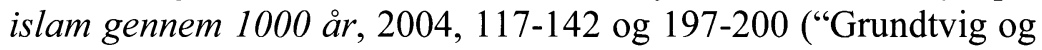
islam").

Slagstad, Rune, Ove Korsgaard \& Lars Løvlie (red.), Dannelsens forvandlinger, Oslo, 2003, 440 s. (Heri bl.a.: "Indledning", 9-36 [om G s. 25-28]; Ove Korsgaard, "Den store krigsdans om kirke og folk", 53-71; Uffe Jonas, "Poetisk videnskab - Grundtvig og Foucault", 125-151).

Stefánsson, Finn, Gyldendals leksikon om nordisk mytologi, 2005, 8285.

Stokholm, Bo, "Om opfattelsen af den naturlige kærlighed hos Grundtvig og Løgstrup" i Mogens Pahuus (red.), Punktnedslag $i$ dansk livsfilosofi, 2001, 133-143.

Stræde, Johs., Tonestigen mellem Jord og Himmel. Glimt fra Grundtvigs salmeverden, 2004, 81 s. (Anm.: Carsten BachNielsen, Kristeligt Dagblad 27.4.2004).

Sørensen, Knud, "Om at være dansk" i hans, Hvor bor kulturen? - og andre funderinger, 1994, 75-86. (Om 1840'ernes Goldschmidt/Grundtvig-diskussion).

Thing, Morten, "Løver og abekatte. Eller hvad er danskhed?" I hans, Den historiske jøde. Essays \& ordbog, 2001, 12-25. (< Social Kritik, nr. 82, 2002, 57-68). 
Thomsen, Niels, "Den grundtvigske vækkelses nadversyn" i Kirsten Busch Nielsen (red.), Nadver og folkekirke, 2002, 33-47.

Thomsen, Niels, "Grundtvig og Bibelen" i Niels Thomsen \& Henrik Brandt-Pedersen (red.), Det står skrevet. Essays om 2000 års bibelfortolkning, 2004, 35-47.

Thorkildsen, Dag, m.fl., Grundtvigianisme og nasjonalisme $i$ Norge $i$ det 19. århundre, Oslo, 1996, 289 s. (KULTs skriftserie, nr. 70). (Især kap. 2, "Nicolaj Frederik Severin Grundtvig", 31-58 og 241245, samt kap. 3, "Grundtvig og Norge", 59-107 og 246-248).

Thyssen, Peter, "Grundtvig-salmerne i Forslag til ny salmebog" i Kommentar til Forslag til ny salmebog. [...] Udarbejdet af et udvalg under bestyrelsen for Samfundet Dansk Kirkesang, 2000, 36-65.

Torm, Axel, Han sang Israels Guds salmer, 1985, 24 s. (Kirken og Jødedommen. Den danske Israelsmissions småskrifter, 3).

Vind, Ole, "Lehmanns bog om Grundtvig" i Erik Reenberg Sand \& Jørgen Podemann Sørensen (red.), Edvard Lehmann og religionshistorien. Et symposium ved fagets 100-års jubiloeum $i$ Danmark, 2001, 79-88.

Wigh-Poulsen, Henrik, “'Hør mig, I fjerne øer’. Esajas, Grundtvig og det danske landskab" i Else K. Holt (red.), Alle der ånder skal lovprise Herren! Det Gamle Testamente i tempel, synagoge og kirke, 1998, 259-286.

Wigh-Poulsen, Henrik, Hjemkomsten og det åbne land. Jakob Knudsens forfatterskab og den grundtvigske realisme, 2001, $248 \mathrm{~s}$. (Ph.D.-afhandling, Aarhus Universitet 2000; let revideret). (Heri: "Grundtvigs realisme", 47-112). (Anm.: Finn Jacobi, Dansk Kirketidende, CLVII, 2002, 42-44; cf. Bent Christensen, ibid., 135-138).

Wigh-Poulsen, Henrik (red.), Folkelighed år 2000. 1. del: Konference afholdt på Vartov den 28. og 29 april 2000; 2. del: Konference afholdt på Vartov den 16. og 17. marts 2001, 2001-02, 47, $44 \mathrm{~s}$. (Vartovs konferenceserie, nr. 1-2). (Heri bl.a.: Niels Henrik Gregersen, "Den generøse ortodoksi", 1, 23-32; Kim A. Pedersen, "Hvad er folkelighed? Glimt af folkelighedsbegrebets historie", 2, 26-40).

Zerlang, Martin, "Grundtvig. Et vidunder i verdenshistorien" i hans, Bylivets kunst. København som metropol og miniature, 2002, 4554.

Østergård, Uffe, "Grundtvig og national identitet" / "Grundtvig og grundtvigianismen" i hans, Europas ansigter. Nationale stater og politiske kulturer $i$ en ny, gammel verden, 1992, 46-48 og 66-69. 


\section{Tidsskriftartikler}

Adamsen, Johannes ,"Herder og Grundtvig - sonderinger". GrundtvigStudier 2001, 166-190.

Albertsen, Andrés R., "El descubrimiento incomparable del teólogo danés N. F. S. Grundtvig". Cuadernos de Teologia (Buenos Aires), XX, 2001, 101-114.

Albertsen, Leif Ludwig, "En metrisk baseret formanalyse af Grundtvigs salme 'Paa Guds Naade"”, Danske Studier, 2005, 187-193.

Allchin, A. M., "Descent into Hell", Grundtvig-Studier 2001, 31-40. (Om Joakim Skovgaards "Kristus i de Dødes Rige").

Allchin, A. M., "Grundtvig's Vartov Sermons. An appreciation". Grundtvig-Studier 2005, 221-224.

[Anonym] "Grundtvig har anfægtelser men genfinder troen". Fogtdals Illustreret Tidende. Guldalderen. Billeder if danskernes liv, 2002, nr. 1, 4-5.

[Anonym] "Grundtvig idømmes livsvarig censur". Fogtdals Illustreret Tidende. Guldalderen. Billeder af danskernes liv, 2003, nr. 1, 4-5.

[Anonym] "Grundtvig vil folkeoplysning og den eksamensfri højskole". Fogtdals Illustreret Tidende. Guldalderen. Billeder af danskernes liv, 2005, nr. 8, 14-15.

Andersen, Balder Mørk, "Grundtvigs folkelighedsbegreb". GrundtvigStudier 2003, 65-87.

Andersen, Nils Erik, "Fædrelandsfølelser og sur-sød satire. Omkring en kendt episode fra den slesvigske sprogstrid", Sønderjysk Månedsskrift, 2002, 249-256. (Om G's hyldestvise til Peder Hiort Lorenzen, 1843).

Balle, Thorstein, "Find dig i fællesskabet! Om Grundtvig, folkestyret og moderne medborgerskab", Dansk paedagogisk Tidsskrift, 2005, nr. 4, 28-37.

Balling, Jakob, "Nedfarten til dødsriget", Grundtvig-Studier 2001, 7075.

Balslev-Clausen, Peter, "Davids-salmer gendigtet på dansk", Hymnologiske Meddelelser, XXXI, 2002, 1-48, spec. 35-45 ("B. S. Ingemann og N. F. S. Grundtvig").

Balslev-Clausen, Peter, "Den dybe sammenhæng. Om Grundtvigs forfatterskab. I anledning af de 222 år", Dansk Kirketidende, CLVII, 2005, 381-382 og 386-387.

Bertelsen, Otto, "Samtalen mellem Grundtvig og Kierkegaard", Grundtvig-Studier 2003, 204-212.

Bhattacharya, Asoke, "N. F. S. Grundtvig. Educationist extraordinary. Homage of an Indian adult educator", Grundtvig-Studier 2005, 192-207.

Birkelund, Regner, "Oplysning og oplysning er to ting!", Klinisk Sygepleje, XIV:1, 2000, 7-12. 
Birkelund, Regner, "Kend dig selv. Om det sociale individ og det sunde samfund", Grundtvig-Studier 2005, 125-143.

Bradley, S. A. J., "Four English Translations of Grundtvig's Hymns", Grundtvig-Studier 2001, 15-24.

Bradley, S. A. J., "Nicolaj Frederik Severin Grundtvig (1783-1872)",

The Cambridge Quarterly, XXXI, 2002, 307-325.

Bradley, S. A. J., "A letter home: Grundtvig in Cambridge to his wife Lise, June 1831". Grundtvig-Studier 2002, 74-80.

Bradley, S. A. J. (overs.), "The Land of the Living”, Grundtvig-Studier 2002, 153-156.

Bradley, S. A. J., "Grundtvig's 'Land of the Living' and Anglo-Saxon scholarship in the Royal Library of Copenhagen", GrundtvigStudier 2002, 157-183.

Bradley, S. A. J., "An Englishman in Vartov Church, 1872. Edmund Gosse, 'Two Visits to Denmark 1872, 1874' (London, 1911), Ch. v, 78-87", Grundtvig- Studier 2003, 160-165.

Bradley, S. A. J., "Before Irenaeus. The Making of Grundtvig the Medievalist", Grundtvig-Studier 2004, 234-254.

Bradley, S. A. J., "Grundtvig's Use of the Exeter Book's Billed-Sprog. The Case of 'Rune-Bladet' and 'Rune-Kiævlet"'. GrundtvigStudier 2004, 255-266.

Bradley, S. A. J., "“To establish a free and open forum'. A memoir of the founding of the Grundtvig Society", Grundtvig-Studier 2005, 13-37.

Brun, Jens, "Udkast til en Grundtvigsk Religionsteologi", Prasteforeningens Blad, LXXXXI, 2001, 770-776.

Bugge, K. E., "Menneske først. Grundtvig og hedningemissionen", Grundtvig-Studier 2001, 115-165.

Bugge, K. E., "Grundtvig and the abolition of slavery", GrundtvigStudier 2005, 160-191.

Bøye, Merete, "Nyaar i den Danske Kirke 1839-40", Hymnologiske Meddelelser, XXXI, 2002, 201-222.

Cappelørn, Niels Jørgen, "Gudbilledlighed og syndefald. Aspekter af Grundtvigs og Kierkegaards menneskesyn på baggrund af Irenæus", Grundtvig-Studier 2004, 134-178.

Chase, Martin, "True at Any Time. Grundtvig's Subjective Interpretation of Nordic Myth", Scandinavian Studies, LXXIII, 2001, 507-34.

Christensen, Bent, "En lokal Grundtvig-kritik anno 1817. Et læserbrev i 'Lolland-Falsters Stifts Kongelig priviligerede Addresse-Contoirs Efterretninger' nr. 33/1817', Stiftsbog og landemode-akt for Lolland-Falsters stift, 1997, 69-76.

Christensen, Bent, "At kende Gud i livets almindelige gudstjeneste", Stiftsbog og landemode-akt for Lolland-Falsters stift, 1998, 33-38.

(Præsentation af forf.'s G-disputats, 1998). 
Christensen, Bent, "Livsvidenskabelig efterskrift [til 'Omkring Grundtvigs Vidskab']”, Dansk Kirketidende, CL, 1998, 164-167, 180-183.

Christensen, Bent, “Om 'Omkring Grundtvigs Vidskab'. Indledningen ved forsvaret den 4. september 1998 og replikker til de to officielle opponenter", Grundtvig-Studier 2001, 191-220.

Christensen, Torben \& Anja Mortensen, "Historie og selvforståelse", Den frie Larerskole, XXXXVII:4, 2001, 21-29. (Med udgangspunkt i speciale om historievidenskabens erkendelsesinteresse set $\mathrm{i}$ lyset af N. F. S. Grundtvigs og Paul Ricoeurs tænkning).

Constantinescu, Codrut, "Portretul unui reformator: N. F. S. Grundtvig”, Axioma (Ploiesti), nr. 60, marts 2005, 17-19.

Damsholt, Torben, "Ej til hovedstæder? Grundtvigske miljøer i København", Vartovbogen, 2002, 15-26.

Drejergaard, Kresten, "Kirken som Betlehem og himmerige", Fyens Stiftsbog, 2002, 71-80.

Elsig-Pedersen, Torben, "Grundtvigs sang til livet", Efterskolen, 2000, nr. 1, 16-18. (Interview med Ebbe Kløvedal Reich).

Engberg, Poul, "Historiens poesi", Vartovbogen, 2004, 65-83.

Engberg, Poul, "Dette her grundtvigske", Vartovbogen, 2005/6: Gud og politik, red. Jørgen Carlsen, m.fl., 191-221.

Eskedal, Anders, “'Den Gamle' som præst, eller et blik ind i N. F. S. Grundtvigs præstevirke især i perioden efter sygdommen 1867", Grundtvig-Studier 2003, 126-159.

Gaunt, Alan,"Translated from N. F. S. Grundtvig", Grundtvig-Studier 2001, 25-30.

Gregersen, Niels Henrik, "Guds frie nåde, troens frie gensvar. Frelsens betingelser hos N. F. S. Grundtvig og John Wesley", GrundtvigStudier 2004, 103-133.

Gaarsted, Max, "Lyset i danske salmer og sange, 3: Lyset hos Ingemann og Grundtvig”, Dansk Sang, LII, 2001-02, nr. 6, 12-18.

Hansen, Søren Peter, "Lærte os så at smile", Dansk Kirketidende, CLVI, 2004, 23-24. (Om smilet i G's salmer).

Haystrup, Helge, "Grundtvigs 'mageløse opdagelse' som patristisk inspiration", Refleks (Filosofisk Institut, Odense Universitet), nr.

32, 1999, 46-61, nr. 33, 2000, 53-71, og nr. 34, 2000, 23-42.

Heggem, Synnøve, “Troen som skolesak - ?!”, Folkehøgskolen, 2005, nr. 8-9, 4-7. (Forkortet version af foredrag ved G-seminar i Hurdal, sept. 2005).

Holm, Anders, "Historiens hjertelyd - Grundtvig og nutidens historiesyn", Højskolebladet, 2001, nr. 17, 3-6.

Holm, Anders, "Historien i øjeblikket og øjeblikket i historien", Vartovbogen, 2004, 139-154. (Om G og Søren Kierkegaard).

Holm, Jakob, "N. F. S. Grundtvig som folke- og religionsteolog. Et eksempel på et teologisk perspektiv på det multi-etnisme og det 
multi-religiøse", Prcesteforeningens Blad, XCII, 2002, 210-216.

Holm, Jette, "'Psalme-Blade til Kirke-Blod'. En brevveksling mellem

Grundtvig og hans præstevenner i foråret 1843", GrundtvigStudier 2002, 24-73.

Holm, Jette, [Grundtvig prædiker]. Dansk Kirketidende, CLVII, 2005, 85-86, 108-109, 147-148, 239-240, 299-301 og 426-428.

Holm, Jette \& Elisabeth A. Glenthøj (medd.), "Grundtvigs prædiken i

Vartov 1. maj 1844", Grundtvig-Studier 2005, 68-71.

Holm, Jette (medd.), "Breve til og fra Grundtvig, marts-juni 1844", Grundtvig-Studier 2005, 72-85.

Hvidt, Agnete Holm, "Et grundtvigsk natursyn. Eller: Hvad der forsvandt op i den blå luft", Dansk Kirketidende, CLVI, 2004, 299302.

Journal of World Education, XXXIII:2, 2003: Nikolaj Frederik Severin Grundtvig, 1783-1872. Grundtvig's Ideas Today, 38 s. (Indhold: Karl Aegidius, "Grundtvig and His Ideas. Fundamental Ideas and Teaching Methods / Principles in the Folk High School Adult Education in Denmark", 3-8; Ove Korsgaard, "Grundtvig's Ideas on Enlightenment", 9-16; Dani W. Nabudere, "Grundtvig's Folkelighed in the Age of Globalisation", 17-23; Sujit Kumar Paul, "Grundtvig's Ideas Today. Vision of Tagore and Grundtvig towards Education and Development", 24-27; Mitsuru Shimizu, "Beyond Modern Disciplined Society toward Joy of Life. A Meaning of Grundtvigian Movement in Japan as an Advanced Country", 28-31; Lidia Shkorkina, "Grundtvig's Ideas in Russian Federation", 32-34).

Jørgensen, Hans Anker, "Det syngende jeg. Om Halfdan og Grundtvig og Brorson og andre egoer i det syngende folk", Dansk Kirkeliv 2002, 5-10.

Kjærsig, Anders, "Om hørelsen af synet og syn på hørelsen. Lidt om Grundtvig og Kierkegaard”, Højskolebladet, 2000, 3-5.

Korsgaard, Ove (red.), Other Dreams, Other Schools! Around N. F. S. Grundtvig and the Danish Folk High Schools = Journal of World Education, XXXII:2, 2002; 39 s. (Heri bl.a.: "Grundtvig's Educational Ideas. On Tying Bonds and Cutting Knots", 3-10 [2000]; "Grundtvig's Concept of 'Folkelighed' and Livingstone's Concept of Civilisation", 20-22).

Korsgaard, Ove (red.), Images of Grundtvig and Rosendal = Journal of World Education, XXXIV:2, 2004; 23 s. (Med bidrag af Ove Korsgaard, Edicio dela Torre, Asoke Bhattacharya, Mitsuru Shimizu, John Glasse og Ronald J. Manheimer).

Korsgaard, Ove, "Fra tugtemester til skolemester. Om forskelle mellem Luther og Grundtvig", Grundtvig-Studier 2004, 34-61.

Langballe, Jesper, "Den danske sag", Tidehverv, LXXVI, 2002, 111129. (Cf. Kim Arne Pedersen, "Langballe og Grundtvig", Dansk 
Kirketidende, CLIV, 2002, 281-282 og 286-290).

Langgård, Karen, "Jonathan Petersen og Grundtvig", Nordica, XIX, 2002, 83-113. (Om gendigtninger på grønlandsk ved JP [18811961] af Grundtvig-salmer).

Lundgreen-Nielsen, Flemming, “Naar Skyggen er ligest ...", Grundtvig-Studier 2001, 58-69.

Lyby, Thorkild C., "Grundtvigs dannelsesbegreb mellem national dannelse og erhvervsorienteret uddannelse", Grundtvig-Studier 2004, 62-82.

Madsen, Arne Busk, "Delte Grundtvig Luthers syn på loven?", Preesteforeningens Blad, LXXXXIII, 2003, 898-905.

Madsen, Helle Krogh, "Grundtvig og 'det grundtvigske"', Religionsleereren, 2003, nr. 5, 10-13.

Møller, Anders Monrad, "Vejen til Sorø? Forspil til Grundtvigs Højskole på Marielyst", Uddannelseshistorie, 2004, 20-33.

Møller, Jes Fabricius, "Årtusindets dansker", Dansk Kirketidende, CLVI, 2004, 185-186 og 190-191. (Om "Berlingske Tidende"s kåring, hvor H. C. Andersen blev nr. 1 og G nr. 6).

Møller, Jes Fabricius, "Grundtvig og folkehøjskolen i dag. Grundtvig og 'Grundtvig' anno 2004", Grundtvig-Studier 2004, 87-91.

Møller, Jes Fabricius, "Hal Koch og Grundtvig”, Historisk Tidsskrift, CIV, 2004, 391-405.

Møller, Jes Fabricius, "Grundtvigianismen og det grundtvigske som retningspræg i det 20. århundrede", Vartovbogen, 2004, 93-109.

Møller, Kristian Massey, "Jomfru Maria, Patriarken, Luther og Grundtvig", Dansk Kirketidende, CLVI, 2004, 109-113.

Nielsen, Jakob Fløe, "Grundtvigsk og grundtvigsk er to ting", Dansk Kirketidende, CLIV, 2002, 165-166 og 170-171. (Uddrag af foredrag).

Olesen, Ole Burchardt, "Grundtvig og den anglikanske kirke med udsyn til Roskilde Stift", Dansk Kirketidende, CLIV, 2002, 12-14.

Olesen, Ole Burchardt, "Grundtvig og Kierkegaard - to alen ud af et stykke? eller Den zelotiske Grundtvig og hans kirkestormende lærling”, Presteforeningens Blad, LXXXXVI, 2006, 258-266 og 282-292.

Pedersen, Kim Arne, "Et rids af Grundtvig-forskningen og dens stilling i efterkrigstidens Danmark. William Michelsen in memoriam", Grundtvig-Studier 2002, 11-23.

Pedersen, Kim Arne, "Grundtvig på anklagebænken. En redegørelse for hovedlinjer i de sidste ti års danske Grundtvig-reception og deres forhold til centrale motiver i Grundtvigs forfatterskab og dets virkningshistorie", Grundtvig-Studier 2002, 184-251.

Pedersen, Kim Arne, "Grundtvig i modvind", Vartovbogen, 2003, 5372.

Pedersen, Kim Arne, "Grundtvig om samfundspagt, gensidig frihed og 
menneskerettigheder i ca. 1840. Med en kommenteret tekstudgivelse". Grundtvig-Studier 2004, 14-33.

Pedersen, Kim Arne, "Grundtvig og folkehøjskolen i dag. 'Nyt syn på Grundtvig' og den grundtvigske højskoletanke”, GrundtvigStudier 2004, 91-102.

Pedersen, Kim Arne, "Grundtvig og fundamentalismen", GrundtvigStudier 2005, 86-124.

Præstegaard, Betina Hjorth, "N. F. S. Grundtvigs syn på forholdet mellem Skabelse, Åbenbaring og Nærværelse belyst ved en sammenligning med Jürgen Moltmann", Grundtvig-Studier 2002, 81120.

Răducanu, Ion, "Nicolai Frederick Severin Grundtvig (1783-1872), 150 ani de la naşterea lui", Paideia (Bucarest), 2002, nr. 2, 35-38. (Optryk af artikel fra 1933).

Rothstein, Mikael, "Maharishi Mahesh Yogi og N. F. S. Grundtvig. Et kulturmøde i ånden", Chaos. Dansk-norsk tidsskrift for religionshistoriske studier, X, 1988, 81-94.

Rykind-Eriksen, Mads, "Arven fra Grundtvig", Dansk Kirketidende, CLIV, 2002, 329-330 og 334-335.

Salomonsen, Preben, "Romantikken i salmerne. Et par notitser til salmerne: 'Skyerne gråner, og løvet falder' (733), 'Der står et slot $\mathrm{i}$ vesterled' (775) og 'Kærlighed til fædrelandet' (710)", Prasteforeningens Blad, 2006, 217-220. (G og B. S. Ingemann).

Schiøler, Aage, "Den kirkelige anskuelse som svar til Karon. Randbemærkninger til tre sømandssange af Grundtvig”, Grundtvig-Studier 2004, 179-233.

Slumstrup, Finn, "Er der frihed til hvad som helst i Grundtvigs og Vorherres navn?", Vartovbogen, 2004, 45-64.

Slumstrup, Finn, "Grundtvigs nødvendighed for de frie skoler", Efterskolen, 2004, nr. 15, 12-14.

Stokholm, Anja, "Om forholdet mellem skabelse og syndefald hos Grundtvig og Luther", Grundtvig-Studier 2003, 88-125.

Thodberg, Christian, "Grundtvig", Arsskrift / Carlsbergfondet, 2002, 34-37. (Om støtte til G-forskning).

Thodberg, Christian, "Grundtvigs Prædikener i Vartov. Præsentation af de første 4 bind, 8. september 2003", Vartovbogen, 2004, 155171.

Thodberg, Christian, "Grundtvigs krise i foråret 1844. Forholdet mellem prædiken og salme med henblik på 'Sov sødt, Barnlille”,, Grundtvig-Studier 2005, 38-67.

Thomsen, Lene Frølund, "Livsoplysning og livsfilosofiske perspektiver - et uddannelsesmæssigt modsvar til tidens fokus på kompetenceudvikling", Grundtvig-Studier 2002, 252-262. (Om to bøger af Regner Birkelund).

Thomsen, Niels, "Grundtvig og Billeder", Grundtvig-Studier 2001, 41- 


\section{7.}

Vestergaard, Per, "Hvorfor vil vi gerne vide, om Grundtvig var maniodepressiv?", Bibliotek for Loger, 194, 2002, 197-203.

Warming, Per, "Marievisen' - den hemmelighedsfulde hymne", Folkehøgskolen, 2005, nr. 8-9, 8-10. (Om "Til Marie, min Trolovede").

Wigh-Poulsen, Henrik, "Et grundtvigsk undervognschek", Dansk Kirketidende, CLIV, 2002, 181-182 og 186-188. (Uddrag af foredrag).

Wigh-Poulsen, Henrik, "Grundtvig, grundtvigianerne og besværet med historien", Højskolebladet, 2002, nr. 17, 13-16.

Wigh-Poulsen, Henrik, "Grundtvig og folkehøjskolen i dag. Fløjkrig og vekselvirkning”, Grundtvig-Studier 2004, 83-87.

Wigh-Poulsen, Henrik, "Det fortsatte opbrud - om det grundtvigske i dag", Fyens Stiftsbog, 2004, 56-65.

Wigh-Poulsen, Henrik, "At være grundtvigsk i dag", Dansk Kirketidende, CLVII, 2005, nr. 16, 261-262, 266-269; nr. 17, 284-289.

Wåhlin, Vagn, "Folkelige og sociale bevægelser. Nyere forskningsretninger og kvalitative forståelser. En indkredsning af et vanskeligt historisk problemkompleks", Grundtvig-Studier 2003, 7-44.

\section{Avisartikler}

Auken, Svend, "Det politiske hos Kierkegaard og Grundtvig", Kristeligt Dagblad 3.6.2002.

Brun, Jens, "En kultur i svøb", Kristeligt Dagblad 23.10.2004. (G mellem Luther og Kierkegaard).

Bækhøj, Lene, "Grundtvig er et oliefyr", Kristeligt Dagblad 23.7.2003. (Om skolegang i den Grundtvig-Koldske friskole).

Carlsen, Jørgen, "Grundtvig er stadig en levende samtalepartner", Kristeligt Dagblad 21.1.2004.

Clausen, Bente, "En kirkepolitisk skypumpe", Kristeligt Dagblad 9.7.2003.

Henriksen, Hanne Mølby, "Da Grundtvig blev døbt som mormon", Kristeligt Dagblad 8.3.2004. (Debat: Henning K. Frederiksen, 11.3.2004; Søren Lodberg Hvas, 16.3.2004).

Holm, Jette, "I al sin glans", Kristeligt Dagblad 8.9.2003.

Husted, Jørgen, "Mennesket er ånd", Kristeligt Dagblad 15.1.2005. (Om G og folkeskolens formålsparagraffer).

Højlund, Niels, "Grundtvigs plads i EU", Kristeligt Dagblad 10.6.2004.

Kentorp, Maria, "Hvad skal vi med ham", Berlingske Tidende 11.1.2004. (Interview med Jes Fabricius Møller, Henrik WighPoulsen og Kim Arne Pedersen).

Klit-Johansen, Villy, “Grundtvig og Treårskrigen”, Kristeligt Dagblad 
16.8.2003. (Debat: Kaj Bollmann, 1.9.2003).

Larsen, Ejvind, "Grundtvig - på trods", Information 10.9.2004. (Om

Kaj Thanings G-tolkning).

Larsen, Jesper Eckhardt, "Manden, der gav Grundtvig modspil", Politiken 6.8.2004. (Om J. N. Madvig).

Mikkelsen, Morten, "Grundtvig med nye ord", Kristeligt Dagblad 5.1.2003.

Mikkelsen, Morten, "Tilbage til den åndelige højskole", Kristeligt Dagblad 6.1.2003. (Interview med Ole Vind). (Debat: Kim Arne Pedersen, 15.1.2004).

Munksgaard, Jørn Arpe, "Danskernes provinsialisme", Berlingske Tidende 13.6.2003.

Rasmussen, Thomas Reinholdt, "Derfor bære blus vi med glæde",

Kristeligt Dagblad 20.12.2003. (Om "Skyerne gråner og løvet falder").

Rosendal, Jens, "Grundtvig misforstås i moderne diskussioner", Kristeligt Dagblad 10.1.2004. (Debat: Christian Stokbro Karlsen, 14.1.2004).

Thing, Morten, "Grundtvig, Goldschmidt - og Langballe", Information 6.2.2004.

Thomsen, Niels, "Da Grundtvig tabte terrinen", Kristeligt Dagblad 8.7.2004. (Om censurkendelsen 1825).

Tjørnehøj, Henning, "Den ufolkelige Grundtvig", Berlingske Tidende 13.2.2004.

Tjørnehøj, Henning, "Grundtvigs amputerede frihedstanke", Kristeligt

Dagblad 12.5.2004. (Debat: Ricardt Riis, 15.5.2004).

Tjørnehøj, Henning, "Grundtvigs sociale blindhed", Kristeligt Dagblad 3.6.2004.

Vind, Ole, "I Grundtvigs fædreland", Politiken 8.9.2002.

Vind, Ole, "Arven Athen og Jerusalem". Politiken 6.5.2004.

Wigh-Poulsen, Henrik, "Grundtvig i Indien, I-II", Kristeligt Dagblad 14.1. og 14.2.2003.

Ågerup, Martin, “Langt højere dværge ...”, Information 4.9.2002.

\section{Varia}

Abrahamowitz, Finn, Grundtvig. Danmark til lykke, 2000. (2. udg., 2003; 413 s.).

Andersen, Pia, "N. F. S. Grundtvig", Forfatterweb, 2005.

Arffmann, Birgitte, "Grundtvigianere og missionsfolk i Vejle", Vejlebogen, 2003, 45-55.

Aspel, Gudrun \& Birgitta Östlund (red.), Nordisk självbild. Nordisk identitet sedd inifrån. Bidrag till en internordisk diskurs, Érica Simon till minne, Göteborg, 2003,126 s. (Heri bl.a.: Kim Arne Pedersen, "Landsbykirke, katedral og Højbro. Om nordisk iden- 
titet, samfundskultur og europæisk samarbejde i lyset af Erica Simons virke", 103-125).

Balslev-Clausen, Peter, "De salmer man skal kende for at kunne synge med", Hymnologiske Meddelelser, XXXIII, 2004, s. 191-214.

Blutsch, Astrid, N. F. S. Grundtvig dänischer Pfarrer und Dichter von der lutherischen Orthodoxie bis zur "Kirkelig Anskuelse", beleuchtet durch Predigten und Psalmen, Diplomarbeit, Evangelisch-Theologische Fakultät der Universität Wien, 2004, 117 s.

Bradley, S. A. J., "Review Article: Between Babel and Globalisation", Grundtvig-Studier 2003, 224-229.

Bradley, S. A. J, "East and West, Tagore and Grundtvig. Report on the Second Grundtvig International Conference on Education \& Development [Jadavpur University, India, January 2003]", Grundtvig-Studier 2003, 230-232.

Brown, Katherine Marie, Analysis of the Implementation of the Grundtvigian Folk Highschool Ideal within Three Provincial Grundtvigian Finlandssvensk Folk Highschools in Pre-Independence Finland, 1889-1919, Ph.D.-thesis, Loyala University of Chicago, 2001, 460 s. (Cf. DAI, 62A, s. 1756).

Christensen, Johs. H., "Ebbe Kløvedal Reich in memoriam", Grundtvig-Studier 2005, 9-12.

Christiansen, Palle Ove, "Grundtvigs kvart", Skalk, 2004, nr. 2, 14-17. (Om Svend G.).

Cizková, Lucie, Learning for European Co-Citizenship. Danish Contribution to the Educational Aspect of Postnational Identity Formation in Europe, Master's Diploma Thesis, Karls-Universitetet, Prag, 2004, 106 s. (Med afsnit om G.). (CD-rom-tilgængelig i Grundtvig-Biblioteket).

Gleerup, Jørgen, "Grundtvig ud med badevandet?", Højskolebladet, 2000, nr. 13, 3-6. (Om aktuel højskoledebat).

Grundtvig-Studier 2001, red. af Fl. Lundgreen-Nielsen, William Michelsen, Kim Arne Pedersen og Jens Holger Schjørring. 2001, 308 s. ("Fra Grundtvig-litteraturen", 258-285; Peter BalslevClausen, "Grundtvig-Selskabet af 8. September 1947. Årsberetning for året 2000", 286-292; "English Summaries/Danske Resuméer", 293-305).

Grundtvig-Studier 2002, red. af Fl. Lundgreen-Nielsen, William Michelsen, S. A. J. Bradley, Kim Arne Pedersen og Jens Holger Schjørring, 2002. 287 s. (Peter Balslev-Clausen, "Grundtvig-Selskabets årsberetning 2001", 264-269; "English Summaries/Danske Resuméer", 270-283).

Grundtvig-Studier 2003, red. af Fl. Lundgreen-Nielsen, S. A. J. Bradley, Kim Arne Pedersen og Jens Holger Schjørring. 2003, 254 s. (Peter Balslev-Clausen, "Grundtvig-Selskabets årsberetning 2002”, 233-238; "English Summaries/Danske Resuméer”, 239- 
251).

Grundtvig-Studier 2004, red. af Fl. Lundgreen-Nielsen, S. A. J. Bradley, Kim Arne Pedersen og Jens Holger Schjørring, 2004, 313 s. (Peter Balslev-Clausen, "Grundtvig-Selskabet af 8. September 1947. Årsberetning 2003”, 289-293; "English Summaries/Danske Resuméer", 294-311).

Grundtvig-Studier 2005, red. af Jens Holger Schjørring, S. A. J. Bradley, Fl. Lundgreen-Nielsen og Kim Arne Pedersen, 2005, 239 s. (Peter Balslev-Clausen, "Grundtvig-Selskabet af 8. September 1947. Årsberetning 2004", 225-230; "English Summaries/Danske Resumeer", 231-239).

Grundtvigs liv og tanker. CD-rom tilrettelagt af Kaare Jørgensen og Hans Jørgen Rasmussen, 2004.

Grymer, Claus, "Grundtvig i konfirmandstuen", Kristeligt Dagblad 14.3.2003. (Resumé af foredrag af Asger Gynther Nielsen).

Hansen, Hanne Luplau Kjer, "Classroom Dialogues and Reflections in

Southeast Asia Inspired by Grundtvig's Educational Ideas", Grundtvig-Studier 2003, 166-187.

Hobolth, Nina, "Christen Dalsgaard soin grundtvigsk billedkunstner", Grundtvig-Studier 2001, 76-93.

Holm, Anders, Historie og efterklang, 2001. (Anm.: Stefan Lamhauge Hansen, Fønix, XXV, 2001, 246-249).

Kanon $i$ dansk, Red. af Torben Brostrøm, Suzanne Brøgger og Jens Smærup Sørensen, 2005, bind 1, 380-396, med noter, 602-603.

Kelstrup, Erik, Sandhedsbegrebet hos N. F. S. Grundtvig kritisk vurderet ud fra sandhedsteorier $i$ det 20 'ende århundredes analytiske og hermeneutiske filosofi, ph.d.-afhandling, Aarhus Universitet, 2003. 405 s. (Utrykt).

Klonteig, Olav, "Voksenutdannelse, folkeopplysning og demokrati. Aktuelle og omfangsrike antologier", Grundtvig-Studier 2003, 213-223.

Korsgaard, Ove, Hikari wo motomete. Denmark no seijin kyoiku 500nen no rekishi, overs af Yakakura Naoko, Tokyo, 1999, $507 \mathrm{s.}$ (Original titel: Kampen om lyset. Dansk voksenoplysning gennem $500 \stackrel{\circ}{\mathrm{r}}, 1997)$.

Korsgaard, Ove, "Verden behøver læring for livet. Fra Grundtvig og Livingstone - til globalisering. Om folkeoplysningens skiftende udfordringer", Højskolebladet (særnummer om den globale højskole), 2004, nr. 21, 9-11; Efterskolen, 2005, nr. 10, 16-17.

Krab-Johansen, Bjørn, "Grundtvig på nettet", Proesteforeningens Blad, LXXXXI, 2001, 241-243.

Krab-Johansen, Bjørn, "www.nfs-grundtvig.dk. Lidt om GrundtvigFondens arbejde", Dansk Kirketidende, 2001, 159-161.

Larsen, Peter Nørgaard, "Kristus i de dødes rige - et maleri [af Joakim Skovgaard] og dets kontekst", Grundtvig-Studier 2001, 94-114. 
Lund, Birte Fahnøe \& Ole Kamp, "De grundtvig/koldske skoletanker i nutidigt perspektiv", Efterskolen, 2004, nr. 8, 14-16.

Lundgreen-Nielsen, Flemming, "Forfatterportræt". Arkiv for dansk litteratur.

Lyng, Anders \& Jesper Vognsgaard, "Gandhi, Gijantali - og Grundtvig. Skoler i Indien og Bangladesh kæmper for demokrati og frihed - med danske Grundtvig som forbillede", Højskolebladet, 2003, nr. 1, 7-9.

Meincke, Inga, Vox viva, 2000. (Anm.: Joachim Grage, Skandinavistik, XXXIV, 2004, 66-67; Flemming Lundgreen-Nielsen, Tijdschrift voor Skandinavistiek, XXII, 2001, 437-448).

Nielsen, Mikkel Crone, "“at tale med de døde ...'. Om sækularisering og hermeneutik i Kaj Thanings forfatterskab". Grundtvig-Studier 2002, 121-141. (KT-bibliografi, 142-152).

Nielsen, Mikkel Crone, En teologihistorisk analyse af centrale temaer $i$ Kaj Thanings forfatterskab, med sarligt henblik på holdningen til samtidens kultur- og scekulariseringsdebat. Speciale, Aarhus Universitet, Institut for Kirkekundskab, 2004, 111 s. (Utrykt).

Nielsen, Niels Kayser, "Nationalisme, disciplin og folkelighed i 1800tallets Danmark", Grundtvig-Studier 2003, 45-64.

Nymark, Annelise, "Bliv klogere på livet - med Grundtvig. Orientering om et undervisningsprojekt for folkeskolens 8.-9. klassetrin", Dansk Kirketidende, CLVI, 2004, 71-73.

Pedersen, Kim Arne, "Anders Pontoppidan Thyssen in memoriam", Grundtvig-Studier 2004, 5-13.

Pedersen, Kim Arne, "Præst i en gammel grundtvigsk valgmenighed", Arhus Stift, 2004, 68-79.

Et responsum udarbejdet af et udvalg nedsat af larerrådene ved Dansk-Bibel-Institut og Menighedsfakultetet, [2001]. (Om tilbageføringer af Kingo, 17-49; Brorson, 49-83 og Grundtvig, 8386).

Riis-Søndergaard, Laust, "Den grandtvigske midtbane. Nye initiativer skal trække Grundtvig ud af mørket", Højskolebladet, 2003, nr. 9, 6-8. (Interview med Kim Arne Pedersen).

Riis-Søndergaard, Laust, "Grundt-video. Nyt cd- og videoprojekt skal udbrede kendskabet til Grundtvig og højskolen", Højskolebladet, 2003, nr. 11, 18-19.

Rømhild, Lars P., N. F. S. Grundtvig: De levendes land, 2004. Nettilgængelig: $w w w . d o w n l a a n . d k$

Sacalis, Nicolae, N. F. S. Grundtvig [...], 1999. (2. let forøgede udg., $2000 ; 281 \mathrm{~s}$.$) .$

Schjørring, Jens Holger, "Anders Pontoppidan Thyssen 17.7.192124.4.2004" i Aarhus Universitet Arsberetning 2004, 963-965.

Stecher-Hansen, Marianne, [Anm. af Gerald M. Haslam, N. F. S. Grundtvig's 'Fadrenearv' (1783-1815), 1998]. Scandinavian 
Studies, LXXIV, 2002, 91-93.

Thomsen, Niels, "For menneskelivets skyld - om Kaj Thaning", Vends. Arbog for Lokal- og Kulturhistorie på Nordvestfyn, 2004, 44-50.

True, Henrik, "Leif Grane in memoriam (1928-2000)", GrundtvigStudier 2001 9-14.

Wåhlin, Vagn, "Folkeoplysning og ungdomsliv. Et indlæg ud fra

Søren Ehlers: 'Ungdomsliv' (2000)”, Grundtvig-Studier 2003, 188-203.

Wåhlin, Vagn, "Folk, dannelse og styreform. En anmeldelse af Ove

Korsgaard, 'Kampen om folket' (2004)", Grundtvig-Studier 2004, 2004, 267-288.

Ægidius, Jens Peter, "Om Poul Engbergs forfatterskab", GrundtvigStudier 2001, 221-228.

Ægidius, Karl Kristian, "Fundamental Ideas and Teaching Methods.

Principles in the Folk High School Adult Education in Denmark" i

Marek Byczkowski, m.fl. (red.), Folk High School - School for Life, Wiezyca, 2003, 19-31.

Ægidius, Karl Kristian, "Sokrates og Grundtvig kom til Polen", Højsskolebladet, 2004, nr. 8, 15-16. (Om et School-for-Lifeprojekt).

8. Websites

Arkiv for dansk litteratur: http://www.adl.dk (Forfatterportræt af Flemming Lundgreen-Nielsen).

Center for Grundtvigstudier, Aarhus Universitet:

http://www.teo.au.dk/cfg/enhed/praesent/

Forfatterweb:

http://voksne.forfatterweb.dk/publish.php?linknavn=zgrundtvig00

(Forfatterportræt af Pia Andersen).

Grundtvig-Byen: http://www.nfs-grundtvig.dk/

Grundtvig på nettet: http://grundtvigsiden.homepage.dk/

Kirkeligt Samfund Vartov - Grundtvig-Akademiet:

http://www.vartov.dk/ga.shtml

Kirkeligt Samfund Vartov - Grundtvig-Biblioteket:

http://www.vartov.dk/gb.shtml 